\title{
Molecular Docking Study of Some Novel Nitro- imidazo[1,2-b]pyridazine based Heterocyclics on Methicillin Resistant Staphylococcus aureus
}

\author{
P. K. RAMAN, K. MURALI KRISHNA and P. VENKATA RAMANA* \\ Department of Chemistry, Sri Krishnadevaraya University, \\ Ananthapuramu-515 003, A.P., India \\ ramanapv54@gmail.com
}

Received 13 February 2016 / Accepted 26 February 2016

\begin{abstract}
In this work, we selected three dimensional structure of Peptidoglycon which plays an important role in staphylococcus pathway. The protein structures were collected from PDB data bank. From the 3D structures of the proteins, the targeted derivatives were designed. Docking studies was performed with designed ligands from the drug. The drug derivatives docked to the protein by hydrogen boding interactions and these interactions play an important role in the binding studies. Docking results showed the best compounds among the derivatives.
\end{abstract}

Keywords: Antibacterial activity, Docking studies, Peptidoglycon, Nitroimidazo[1,2-b]pyridazine.

\section{Introduction}

Bacteria, including Staphylococcus aureus, can bind opsonically active C3b molecules through activation of the classical as well as the alternative complement (C) pathways. In either case, the fixation of $\mathrm{C} 3$ to the surface of the bacteria seems to be critical for rapid ingestion by phagocytes ${ }^{1,2}$. In normal human serum $S$. aureus opsonization is rapidly mediated via the IgG-dependent classical $\mathrm{C}$ pathway. In the absence of antibody, however, bacterial opsonization proceeds at a significantly slower rate via the alternative $\mathrm{C}$ pathway ${ }^{3}$. Recently attention was focused on peptidoglycan (PG) as being the $S$. aureus cell-wall component of key importance in promoting bacterial opsonization ${ }^{4}$. Purified PG has been found to remove opsonic factors from serum ${ }^{5,6}$, to become rapidly ingested by human polymorphonuclear leucocytes when opsonized ${ }^{7}$ and to consume C3-9 via the classical as well as the alternative $C$ pathways and in the absence of immunoglobulins ${ }^{7,8}$. Teichoic acid (TA) and protein A (PA), the other two major polymers of the cell wall of $S$. aureus, were not included in these studies and their importance in bacterial opsonization was thus assessed only indirectly ${ }^{9}$. Furthermore, the consumption of $\mathrm{C}$ by staphylococci has not been correlated with the process of bacterial opsonization. 


\section{Methodology}

The structures of the compounds (Figure 1) were constructed and optimized using chemsketch software.

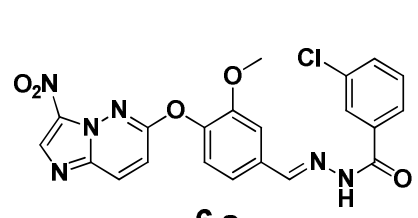

6 a

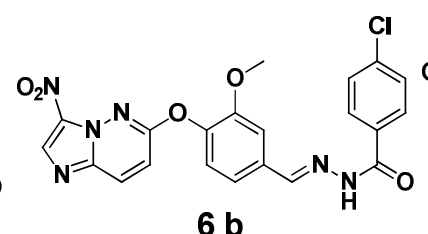

$6 \mathrm{~b}$<smiles>COc1cc(/C=N/NC(=O)c2cccc([N+](=O)[O-])c2)ccc1Oc1ccc2ncc([N+](=O)[O-])n2n1</smiles>

$6 \mathrm{c}$<smiles>C=Nc1cnc2ccc(Oc3ccc(/C=N/NC(=O)c4ccc(OC)c(N=O)c4)cc3OC)nn12</smiles>

$6 \mathrm{~d}$

$6 \mathrm{e}$

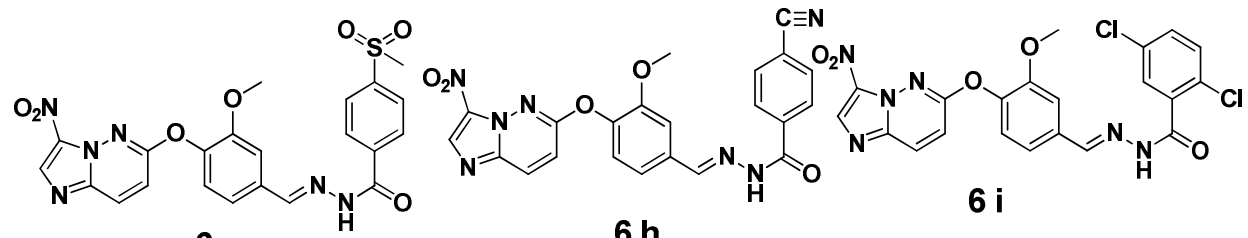

$6 \mathrm{~g}$

$6 \mathrm{~h}$<smiles>COc1cc(/C=N/NC(=O)c2cc(Cl)cc(Cl)c2)ccc1Oc1ccc2nc(N=N/N=C/c3ccc(Oc4ccc5ncc([N+](=O)[O-])n5n4)c(OC)c3)nn2c1</smiles>

$6 \mathbf{j}$

$6 \mathrm{k}$<smiles>COc1cc(/C=N/NC(=O)c2ccccc2I)ccc1Oc1ccc2ncc([N+](=O)[O-])n2n1</smiles>

6 I<smiles>COc1cc(/C=N/NC(=O)c2cccc(-c3nc4ccc(Oc5ccc(/C=N/NC(=O)C6CCCCC6)cc5OC)c([N+](=O)[O-])n4n3)c2)ccc1Oc1ccc2ncc([N+](=O)[O-])n2n1</smiles><smiles>COc1cc(/C=N/NC(=O)c2ccc(C)cc2)ccc1Oc1ccc2ncc([N+](=O)[O-])n2n1</smiles>

60

\section{$6 \mathrm{~m}$}

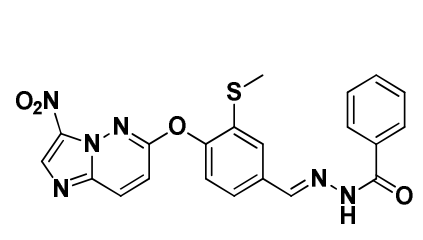

$6 p$<smiles>COc1cc(/C=N/NC(=O)c2cccc(C(C)=O)c2)ccc1Oc1ccc2ncc([N+](=O)[O-])n2n1</smiles>

$6 q$<smiles>COc1cc(/C=N/NC(=O)c2ccc(C(=O)O)cc2)ccc1Oc1ccc2ncc([N+](=O)[O-])n2n1</smiles>

$6 \mathrm{r}$

Figur 1. Compounds used for docking studies

To prepare the peptidoglycon from Staphylococcus, the crystal structure was taken from the Protein Data Bank (PDB_ID: 3NB6) (Figure 2). 


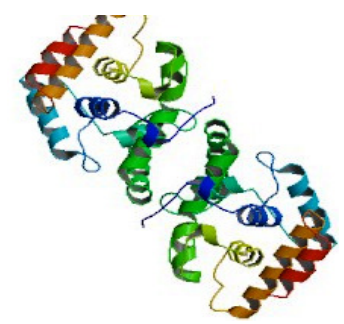

Figure 2. Peptidoglycon

Hetero atoms were removed from the binding site and the chain A was selected for docking studies. Hydrogen atoms were added to the enzyme. The molecular docking method was performed using the Gold version 3.0.1 program to study the binding orientation of compounds into the Sortase structure. The docking experiments were performed using the binding site of Sortase. The binding site identification was carried out using CastP server. A new program, CAST, for automatically locating and measuring protein pockets and cavities, based on precise computational geometry methods, including alpha shape and discrete flow theory was used. CAST identifies and measures pockets and pocket mouth openings, as well as cavities. The program specifies the atoms lining pockets, pocket openings \& buried cavities, the volume $\&$ area of pockets $\&$ cavities and the area $\&$ circumference of mouth openings.

\section{Docking method}

Docking was carried out using GOLD (Genetic Optimization of Ligand Docking) software which is based on genetic algorithm (GA). This method allows partial flexibility of protein and full flexibility of ligand. The compounds are docked to the active site of the protein. The interaction of these compounds with the active site residues are thoroughly studied using molecular mechanics calculations. The parameters used for GA were population size (100), selection pressure (1.1), number of operations $(10,000)$, number of island (1) and niche size (2). Operator parameters for crossover, mutation and migration were set to 100,100 and 10 respectively. Default cutoff values of $3.0 \mathrm{~A}^{\circ}(\mathrm{dH}-\mathrm{X})$ for hydrogen bonds and $6.0 \mathrm{~A}^{\circ}$ for van der waals were employed. During docking, the default algorithm speed was selected and the ligand binding site in the alpha glucosidase was defined within a $10 \mathrm{~A}^{\circ}$ radius with the centroid as CE atom of ASP175. The number of poses for each inhibitor was set 100 and early termination was allowed if the top three bound conformations of a ligand were within $1.5 \mathrm{~A}^{\circ}$ RMSD. After docking, the individual binding poses of each ligand were observed and their interactions with the protein were studied. The best and most energetically favorable conformation of each ligand was selected.

\section{Gold score fitness function}

Gold Score performs a force field based scoring function and is made up of four components: 1. Protein-ligand hydrogen bond energy (external H-bond); 2. Protein-ligand van der waals energy (external vdw); 3. Ligand internal van der waals energy (internal vdw); 4. Ligand intramolecular hydrogen bond energy (internal- $\mathrm{H}$ - bond). The external vdw score is multiplied by a factor of 1.375 when the total fitness score is computed. This is an empirical correction to encourage protein-ligand hydrophobic contact. The fitness function has been optimized for the prediction of ligand binding positions.

$$
\text { Gold Score }=S \text { (hb_ext })+S\left(v d w \_e x t\right)+S\left(h b \_i n t\right)+S\left(v d w \_i n t\right)
$$

Where S (hb_ext) is the protein-ligand hydrogen bond score, $S$ (vdw_ext) is the proteinligand van der waals score, $\mathrm{S}$ (hb_int) is the score from intramolecular hydrogen bond in the ligand and S (vdw_int) is the score from intramolecular strain in the ligand. 


\section{Results and Discussion}

After collecting the crystal structures, the possible binding sites of 3NB6 was searched with CASTP server as shown in Figure 3. The residues included in active site were ILE 110, ASP 111, SER 112, PRO 113, THR 115, TYR 116, GLY 121, TYR 122, LYS 123, ALA 137, LEU 138, PRO 139, PRO 140, VAL 141, ALA 142, CYS 145, GLY 150, LEU 352, GLN 355, GLN 356, PHE 357, GLN 358 and LYS 518.

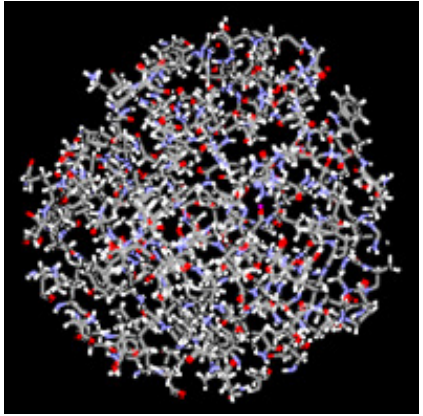

Figure 3. Active site

From the binding site analysis of 3NB6 it was identified that, the binding pockets were identical in all chains and the largest binding pocket was taken for further docking studies. The crystal structure of 3NB6 was similar and hence taken as representative structure for docking studies. The docking of drugs into the active site of 3NB6 was performed using the GOLD software and the docking evaluations were made on the basis of GoldScore fitness functions. The Gold fitness score was preferred rather than Chemscore fitness function as the former is marginally better than later.

\section{Molecular docking study}

Structure-based drug design begins with the identification of a molecular target like a protein such as 3NB6. This structure was then used as a blueprint for the drug design of a lead compound. The compounds were modelled for their fit in the active site of the target, considering both steric aspects (i.e., geometric shape) and functional group interactions, such as hydrogen bonding and hydrophobic interactions. The selected docked conformations of analogues into the 3NB6 binding site are shown in Figure 4.

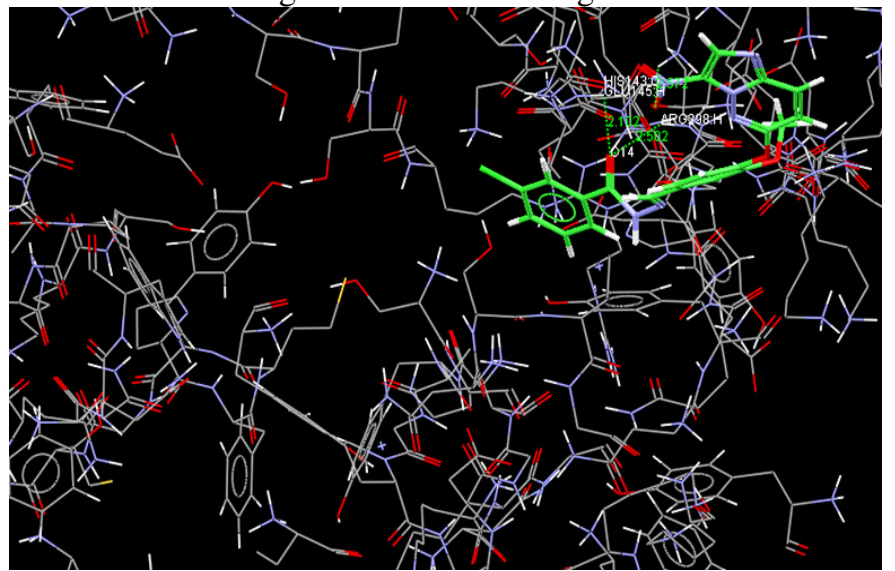

(a)

Docking of 6a 

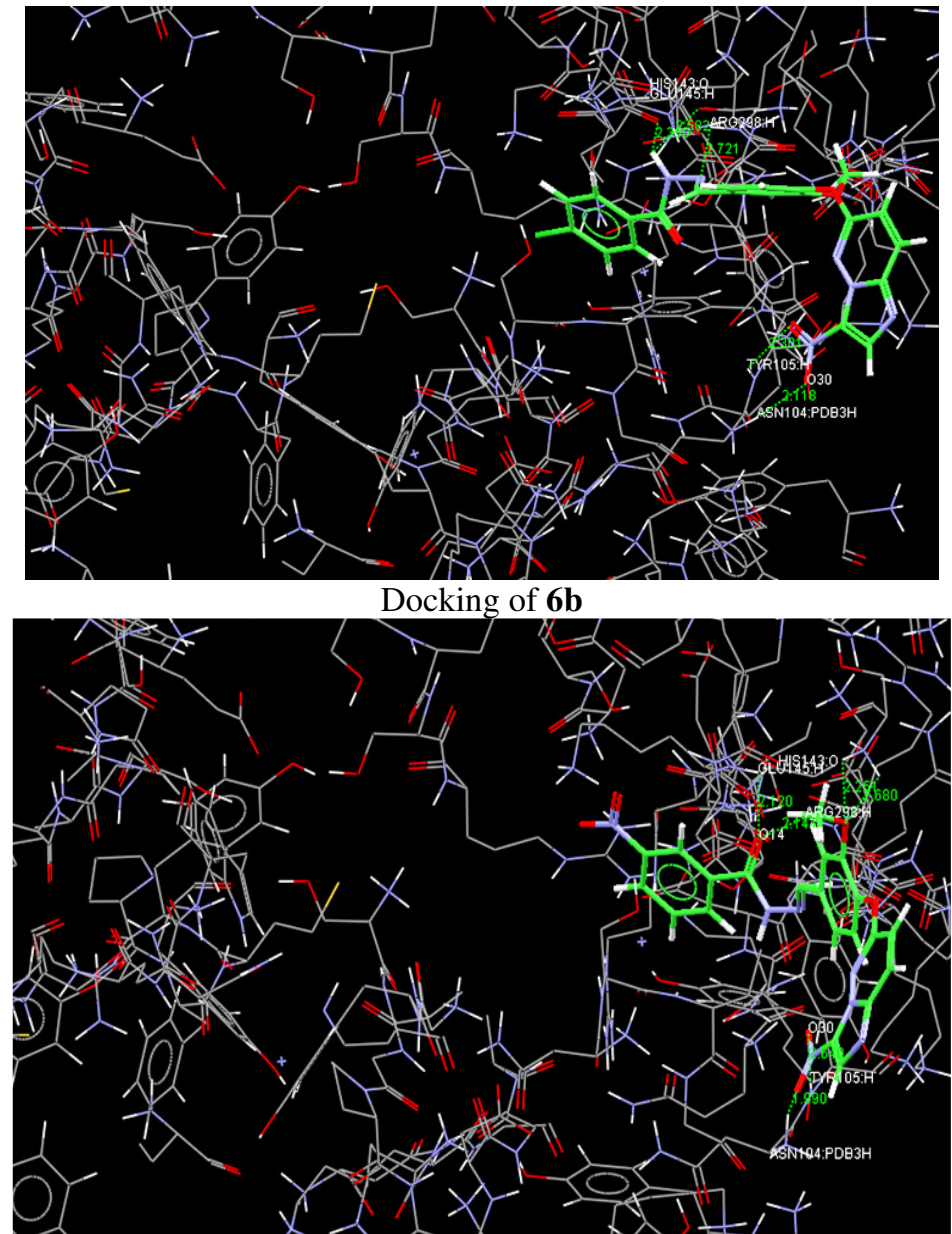

(c)

Docking of $\mathbf{6 c}$

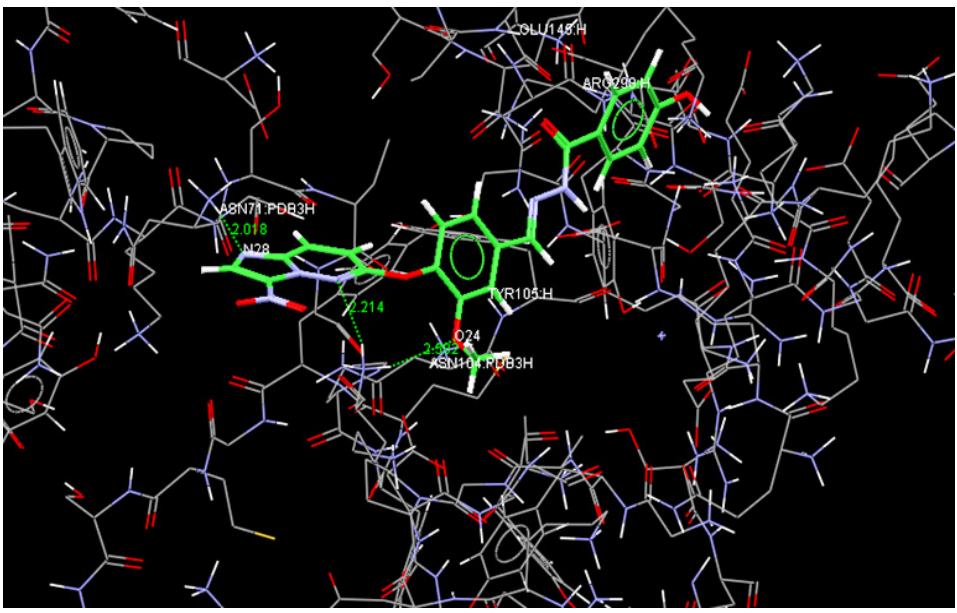

(d)

Docking of 6d 


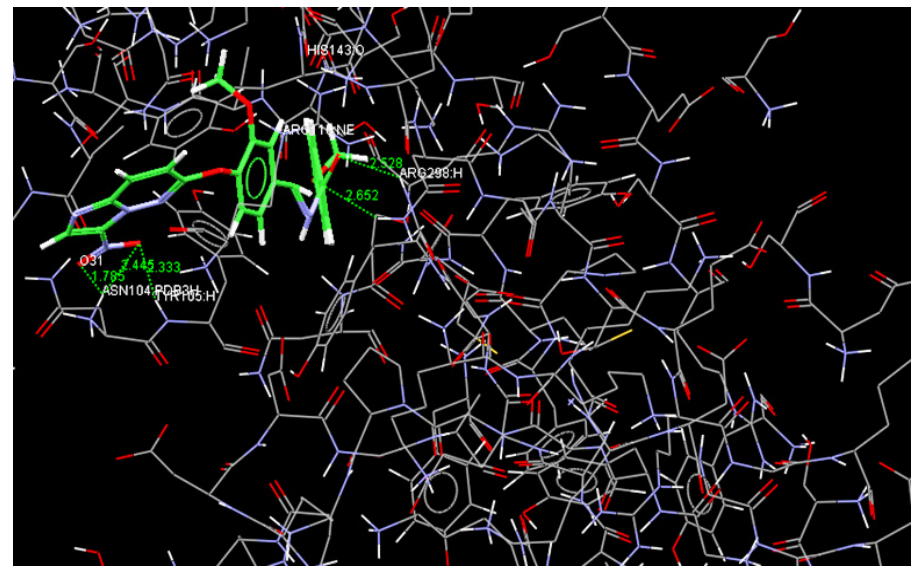

(e)

Docking of $6 \mathbf{e}$

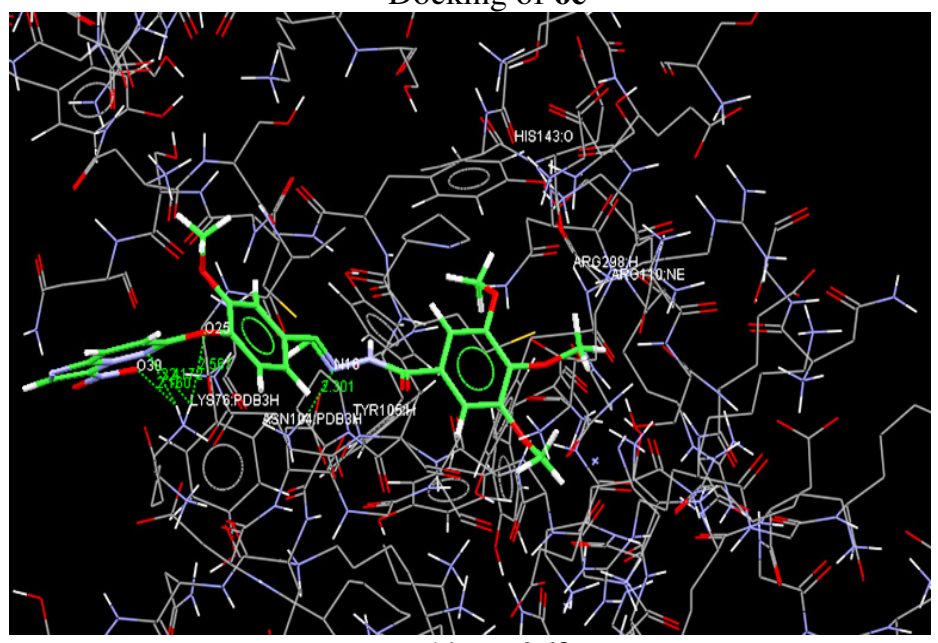

(f)

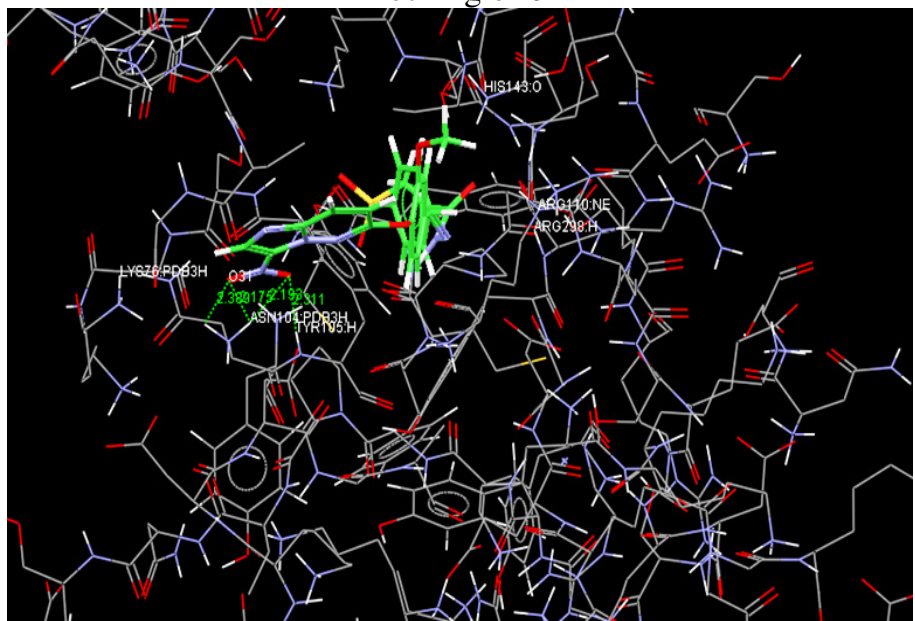

(g)

Docking of $\mathbf{6 g}$ 


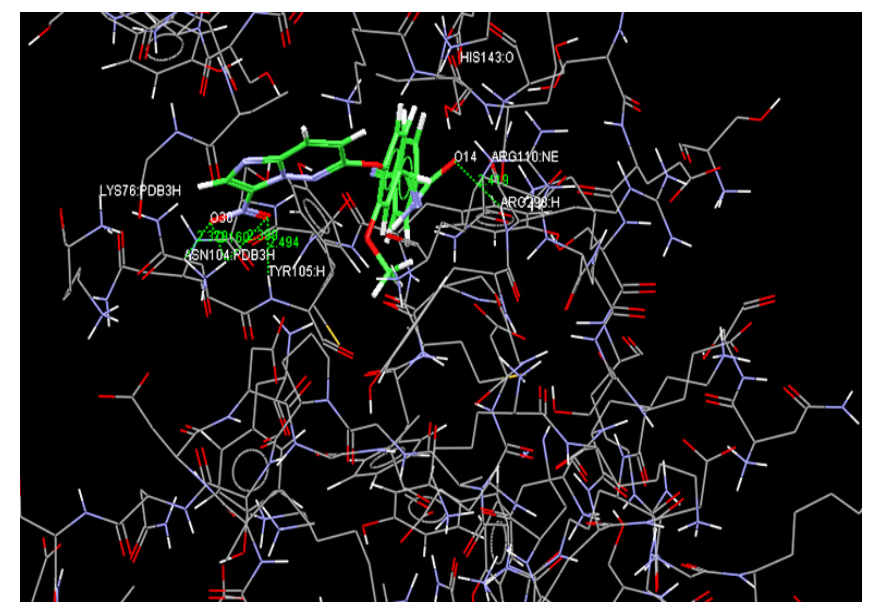

(h)

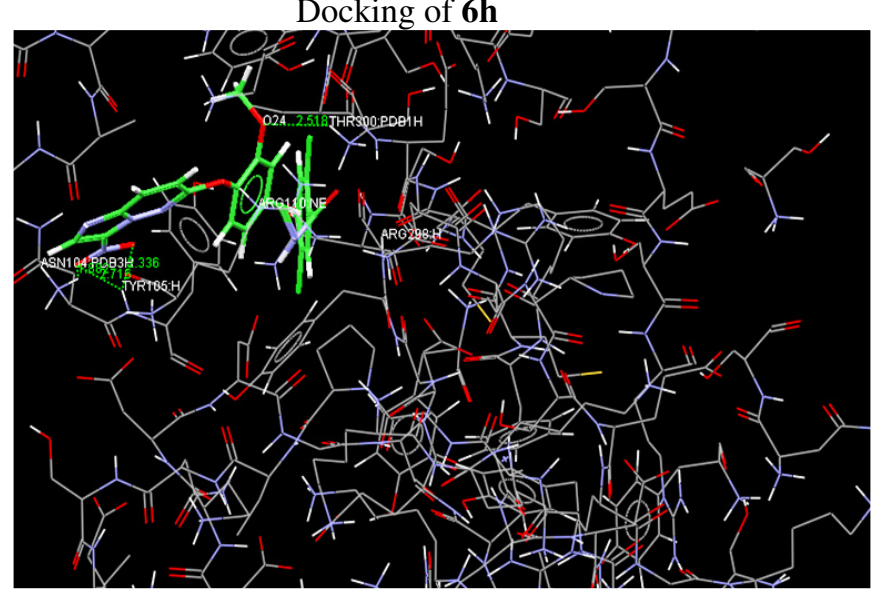

Docking of $6 \mathbf{i}$

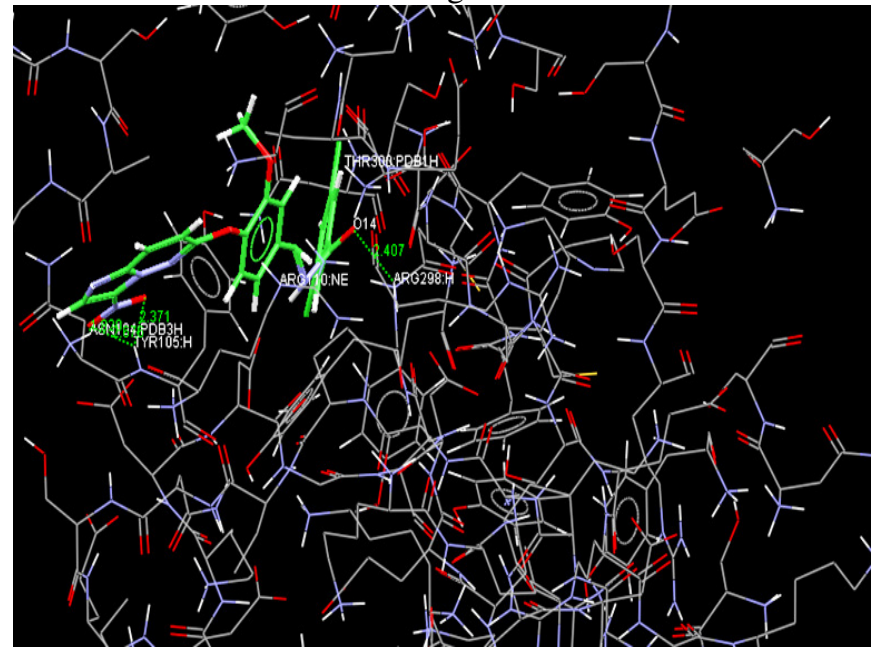

(i)

(j)

Docking of $\mathbf{6 j}$ 


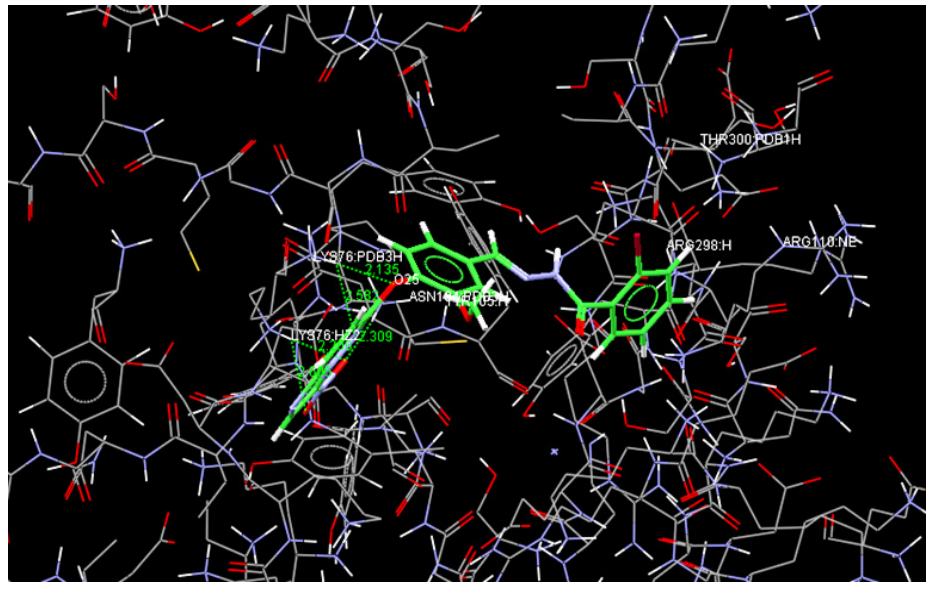

Docking of $\mathbf{6 k}$

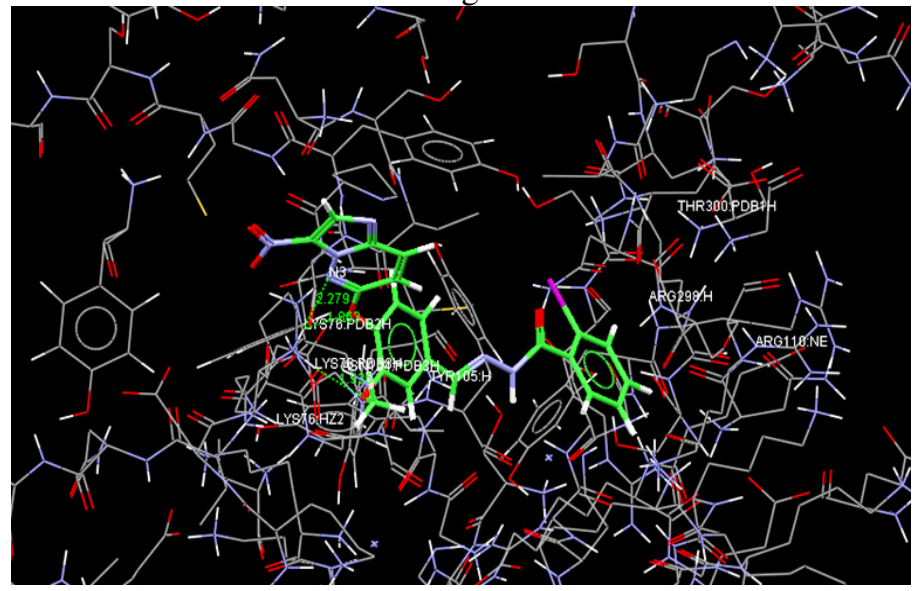

(k)

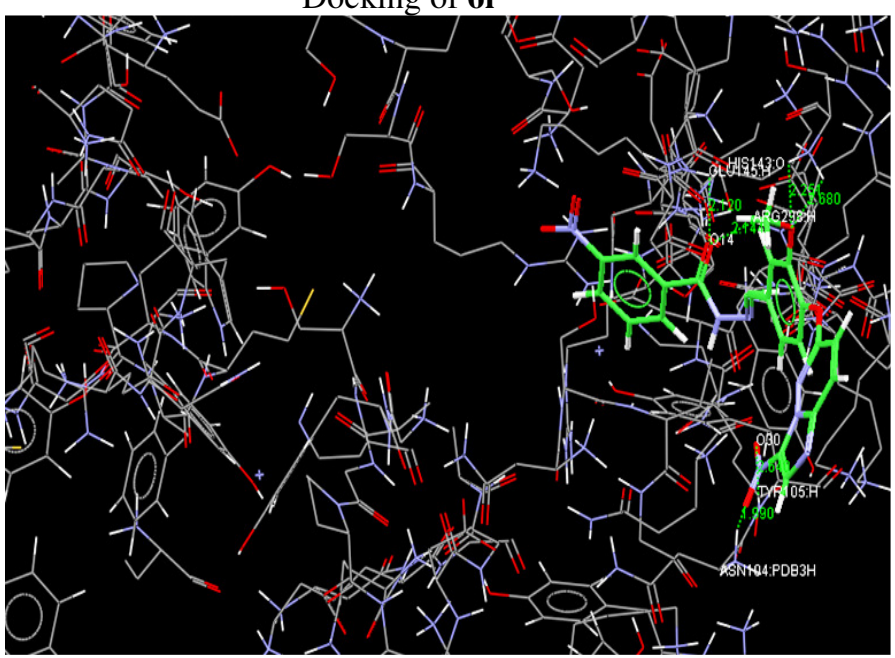

(m)

Docking of $6 \mathbf{m}$

(1) 


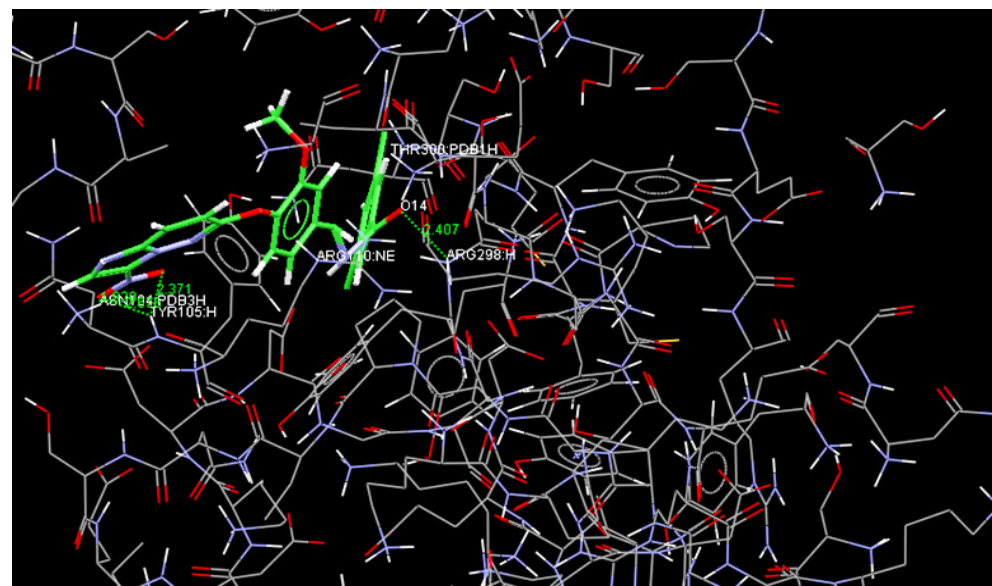

(n)

Docking of 6n

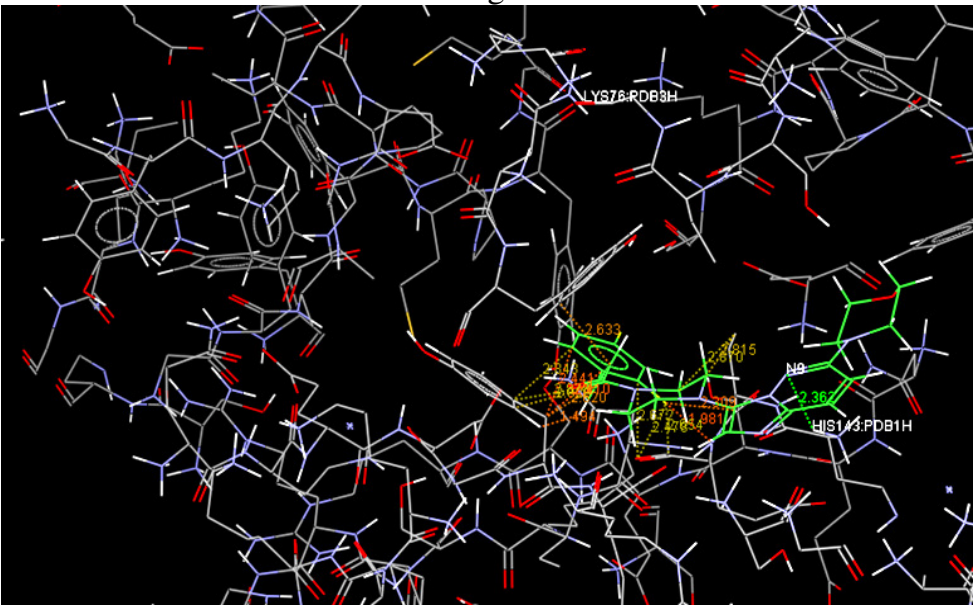

(o)

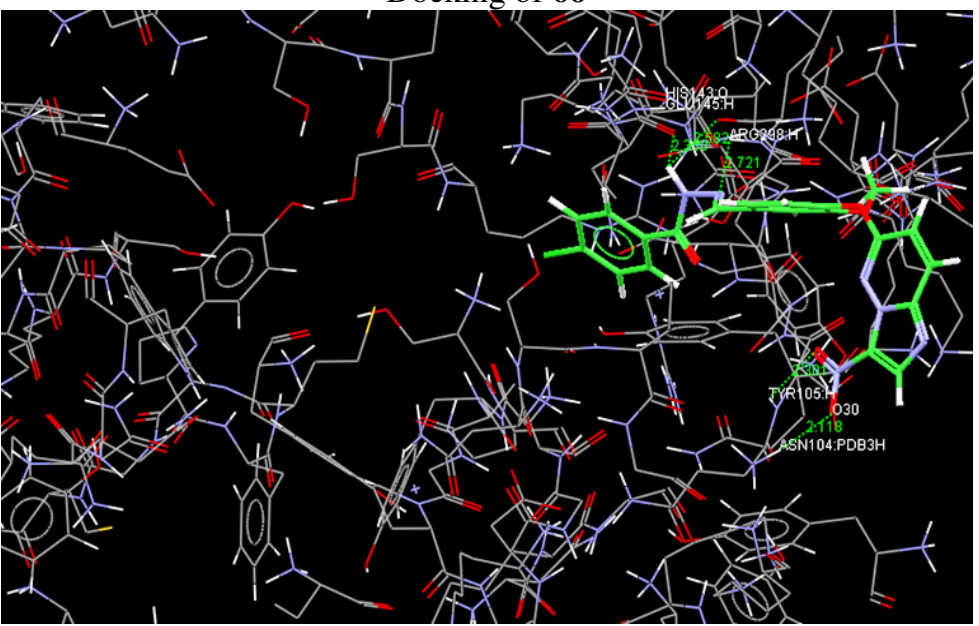

(p)

Docking of $\mathbf{6 p}$ 


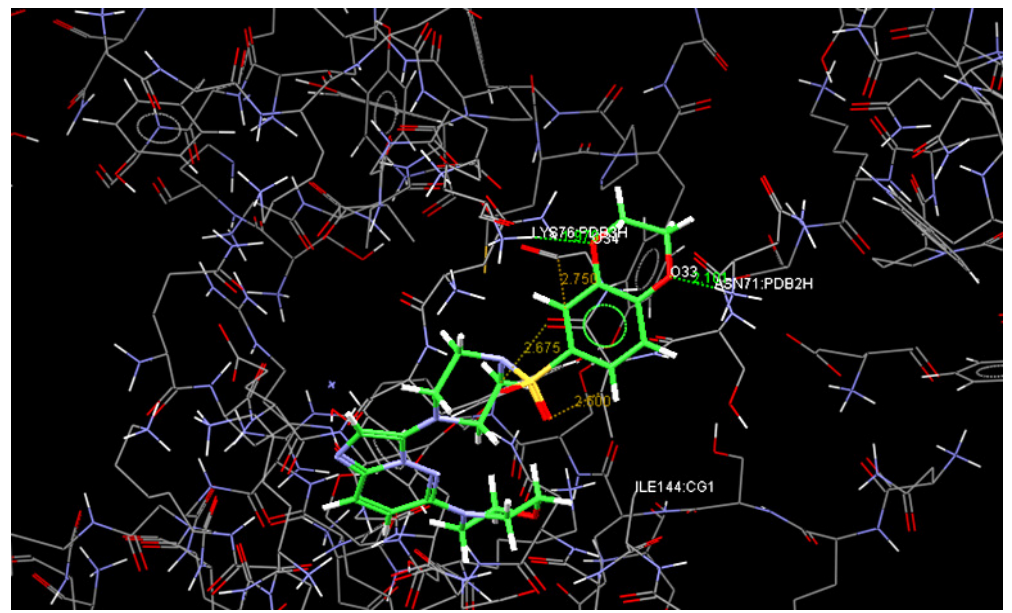

(q)

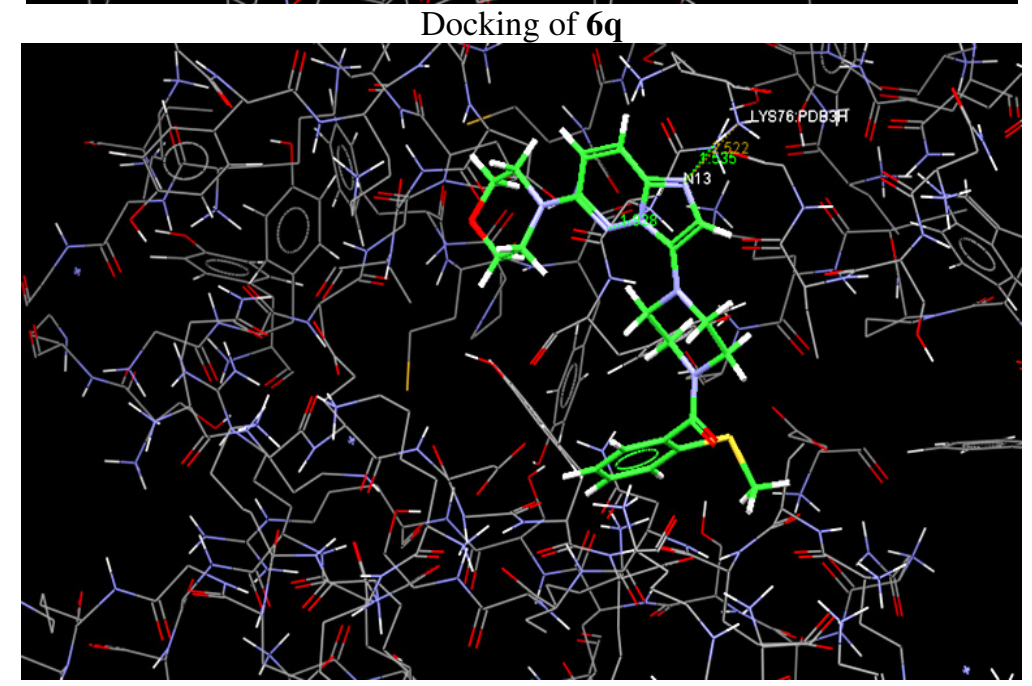

Docking of $\mathbf{6 r}$

Figure 4(a-r). Docking of compounds

The docked conformations revealed that all molecules were located in the hydrophobic binding pocket. All the docked drugs were found to have some interactions between an oxygen atom of the drugs and target protein. Moreover, these docked conformations also formed an $\mathrm{H}$-bonding interaction within the active site (Table 1).

In the binding pocket, common $H$-bonding interactions were formed between all docked drugs and GLY 121, TYR 122, LYS 123 and ALA 137. Inorder to explain the binding of these compounds, the $H$-bonding interactions with the other surrounding residues in the hydrophobic binding pocket were also investigated. In Figure 4, strong $H$-bonding interactions between the hydroxyl group (H12) of analogue and an oxygen atom of GLU31 and another hydrogen bond between hydroxyl group (H11) and oxygen atom of ASP111 were noticed. Two $H$-bonding interactions were also formed between oxygen atom $(\mathrm{O} 4)$ of 5-FU, ASP29 and CYS 44 of 3NB6. 
Table 1. Fitness score

\begin{tabular}{cccccc}
\hline Ligand name & Fitness & S(hb_ext) & S(vdw_ext) & S(hb_int) & S(int) \\
\hline $\mathbf{6 a}$ & 36.24 & 0 & 33.77 & 0 & -10.18 \\
$\mathbf{6 b}$ & 38.4 & 6 & 30.48 & 0 & -9.51 \\
$\mathbf{6 c}$ & 42.21 & 3.94 & 40.79 & 0 & -17.81 \\
$\mathbf{6 d}$ & 43.68 & 9.26 & 30.36 & 0 & -7.32 \\
$\mathbf{6 e}$ & 41.94 & 6.2 & 39.23 & 0 & -18.21 \\
$\mathbf{6 f}$ & 35.21 & 8.99 & 33.74 & 0 & -20.16 \\
$\mathbf{6 g}$ & 38.68 & 8 & 39.02 & 0 & -22.97 \\
$\mathbf{6 h}$ & 41.2 & 5.95 & 39.37 & 0 & -18.88 \\
$\mathbf{6 i}$ & 44.02 & 4.42 & 40.72 & 0 & -16.38 \\
$\mathbf{6 j}$ & 44.46 & 4.45 & 4.68 & 0 & -15.92 \\
$\mathbf{6 k}$ & 41.63 & 18 & 23.38 & 0 & -8.66 \\
$\mathbf{6}$ & 41.51 & 9.17 & 28.38 & 0 & -8.68 \\
$\mathbf{6 m}$ & 21.68 & 5.03 & 32.6 & 0 & -28.19 \\
$\mathbf{6 n}$ & 15.69 & 4.74 & 24.46 & 0 & -22.68 \\
$\mathbf{6 o}$ & 18.71 & 0.63 & 33.58 & 0 & 28.1 \\
$\mathbf{6 p}$ & 31.21 & 8.99 & 33.74 & 0 & 20.16 \\
$\mathbf{6 q}$ & 33.57 & 8 & 39.02 & 0 & 22.97 \\
$\mathbf{6 r}$ & 40.12 & 5.95 & 39.37 & 0 & 18.88 \\
\hline
\end{tabular}

\section{Conclusion}

The docking results agreed well with the observed in vitro data, in which the anti-microbial activity of the analogues was higher than other drugs and formed five hydrogen bonds. The docking study revealed the binding orientation of compounds in the 3NB6 binding pocket surrounding the active site, which resulted in inhibition of enzyme activity. From these results we can conclude that $\mathbf{6 j}$ is one of the good inhibitory compounds of 3NB6. The application of computational sciences to pharmaceutical research is a discipline, which is phenomenal.

\section{References}

1. Gigli I and Nelson R A Jr, Exp Cell Res., 1968, 51(1), 45-67; DOI:10.1016/00144827(68)90158-4

2. Stossel T P, Field R J, Gitlin J D, Alper C A and Rosen F S, J Exp Med., 1975, 141(6), 1329-1347; DOI:10.1084/jem.141.6.1329

3. Verbrugh H A, Van Dijk W C, Peters R, Van Der Tol M E, Peterson P K and Verhoef J, Immunology, 1979, 36(3), 391-397.

4. Kronvall G and Gewurz H, Clin Exp Immunol., 1970, 7(2), 211-220.

5. Humphreys D W, Wheat L J and White A, J Lab Clin Med., 1974, 84(1), 122-128.

6. Pryjma J, Pryjma K, Grov A and Heczko P B, Immunological Activity Of Staphylococcal Cell Wall Antigens. In: Staphylococci And Staphylococcal Diseases (Ed. By Jeljaszewicz J) Gustav Fisher Verlag, New York, 1976, p 873.

7. Peterson P K, Wilkinson B J, Kim Y, Schmeling D, Douglas S D, Quie P G and Verhoef J, J Clin Invest., 1978, 61(3), 597-609; DOI:10.1172/JCI108971

8. Wilkinson B J, Kim Y, Peterson P K, Quie P G and Michael A F, Infect Immun., 1978, 20(2), 388-392.

9. Archibald A R, The Chemistry Of Staphylococcal Cell Walls. In: The Staphylococci (Ed. By Cohen J O), Wiley Interscience, New York, 1972, p 75. 